\title{
Compostos bioativos em café integral e descafeinado e qualidade sensorial da bebida
}

\author{
Sheila Andrade Abrahão(1), Rosemary Gualberto Fonseca Alvarenga Pereira(1), Adriene Ribeiro Lima(1), \\ Eric Batista Ferreira( ${ }^{(2)}$ e Marcelo Ribeiro Malta(3)
}

(1)Universidade Federal de Lavras (UFLA), Departamento Ciência dos Alimentos, Caixa Postal 3037, CEP $37200-000$ Lavras, MG.
E-mail: sheilanutri@yahoo.com.br, rosegfap@ufla.br, biodri@hotmail.com (2)UFLA, Departamento de Ciências Exatas. E-mail: ericbferreira@netscape.net
${ }^{(3)}$ Empresa de Pesquisa Agropecuária de Minas Gerais, CEP 37200-000 Lavras, MG. E-mail: marcelomalta@epamig.br

Resumo - O objetivo deste estudo foi determinar a qualidade sensorial de café (Coffea arabica) descafeinado e integral, os níveis de compostos bioativos, antes e após a torração, e a estabilidade destes após a extração da bebida. A análise sensorial foi realizada por meio do método oficial brasileiro de classificação do café. As análises de cafeína, trigonelina e ácido clorogênico foram realizadas por cromatografia líquida de alta eficiência. O delineamento experimental foi o inteiramente ao acaso, em parcelas subdivididas com quatro tipos de café, cinco tempos de análise e três repetições. Na análise sensorial, foi observado que as características sensoriais, presentes na amostra integral, foram perdidas após o processo de descafeinação. Na variável concentração de trigonelina, não houve diferença significativa entre as amostras integrais e descafeinadas. As concentrações para as amostras de café descafeinado verde e integral torrado não foram alteradas após 4 horas de extração. Houve redução significativa na concentração do ácido clorogênico após a torração, após o processo de descafeinação, e com o decorrer do tempo de extração. Quanto à cafeína, não houve diferença significativa após a torração e nem com o passar do tempo após a extração. A descafeinação e a torração afetaram a qualidade sensorial do café e alteraram a concentração dos compostos bioativos.

Termos para indexação: Coffea arabica, ácido clorogênico, cafeína, trigonelina.

\section{Bioactive compounds in whole and decaffeinated coffee and sensorial quality of the beverage}

\begin{abstract}
The aims of this study were to determine the sensorial quality of both decaffeinated and whole coffee (Coffea arabica), the levels of bioactive compounds, before and after toasting, and bioactive compound stability after beverage extraction. The sensorial analysis was accomplished according to the official Brazilian method for coffee classification. The analyses of caffeine, trigonelline and chlorogenic acid were performed by high performance liquid chromatography. The experimental design was completely randomized with split plot using four types of coffee, five times of analyses and three replicates for each treatment. In the sensorial analysis, it was observed that the sensorial characteristics present in the whole sample were lost after the decaffeination process. For trigonelline, no significant differences were found among the whole and decaffeinated samples. For the samples of toasted whole and green decaffeinated coffee, trigonelline did not vary until 4 hours after the extraction. There was a significant reduction in the concentration of chlorogenic acid after toasting, after the decaffeination process, and over the extraction time. For caffeine, there were no significant differences after toasting or even with the time after extraction. Decaffeination and toasting processes affected the sensorial quality of coffee and altered the concentration of bioactive compounds.
\end{abstract}

Index terms: Coffea arabica, chlorogenic acid, caffeine, trigonelline.

\section{Introdução}

O café é uma bebida de grande popularidade, consumida mundialmente, com aroma e sabor característicos. Por isso, numerosos estudos concernentes à segurança e as implicações dessa bebida na saúde têm sido realizados; e em razão de sua composição química, inúmeras vantagens e desvantagens para a saúde humana lhe têm sido atribuídas.

A composição química dos grãos de café arábica é variável em conseqüência das condições em que foram produzidos e processados. Essa composição depende de fatores genéticos, ambientais e condições de manejo pré e pós-colheita. Segundo Licciardi et al. (2005) a torração é uma etapa essencial para a 
produção de compostos que conferem as características de aroma e sabor ao café, entre os quais destacam-se algumas substâncias biologicamente ativas, ou seja, que exercem benefícios à saúde humana, como o ácido clorogênico, a trigonelina e a cafeína. Entre as atividades biológicas apresentadas por esses compostos citam-se a inibição da biossíntesse dos leucotrienos e os efeitos anticarcinogênico, trófico - sobre a microflora intestinal, estimulante do sistema nervoso central e antidepressivo (Araújo \& Mancini Filho, 2006).

Os ácidos clorogênicos, além das propriedades fisiológicas e farmacológicas que conferem à saúde humana como a atividade antioxidante, são conhecidos por contribuir com o sabor e aroma característicos das bebidas de café. A atividade antioxidante desses compostos deve-se principalmente às suas propriedades redutoras e estrutura química. Estas características desempenham um papel importante na neutralização ou seqüestro de radicais livres e quelação de metais de transição (Daglia et al., 2000; Farah \& Donangelo, 2006; Souza et al., 2007).

A trigonelina é uma N-metil betaína que tem recebido considerável atenção, tanto do ponto de vista sensorial como nutricional, pois tem efeito sobre o sistema nervoso central, e sobre a secreção da bile e a motilidade intestinal (Clarke \& Macrae, 1985). Com sua degradação térmica, há formação de pirróis e piridinas, que são de relevante importância para o aroma do café. Além disso, durante a torração, se converte em vitamina do complexo B (niacina), o que faz do café um dos únicos alimentos que aumenta seu valor nutricional após o processamento térmico (De Maria et al., 1999; Casal et al., 2000).

A cafeína é um alcalóide encontrado em grande variedade de bebidas (chás, cafés, refrigerantes etc.). A cafeína atua no organismo humano principalmente como estimulante do sistema nervoso central e diurético, além disso, aumenta a taxa metabólica, relaxa a musculatura lisa dos brônquios, do trato biliar, do trato gastrintestinal e de partes do sistema vascular. A ingestão de cafeína em excesso pode causar vários sintomas desagradáveis, inclusive a irritabilidade, dores de cabeça, insônia, diarréia e palpitações do coração (Brenelli, 2003). Tal contradição acaba por acarretar aumento do consumo de café descafeinado, muitas vezes por aconselhamento médico (Smith et al., 1992; D'avanzo et al., 1993; Klatsky et al., 1993; Kawachi et al., 1994).
A descafeinação é realizada nos grãos crus inteiros, antes do processo de torrefação. A maioria dos métodos de descafeinação existentes utiliza solventes para extração da cafeína, como diclorometano, clorofórmio, álcool, acetona, água e outros; no Brasil, o diclorometano é o mais utilizado (Toci et al., 2006).

Durante a extração da cafeína, com uso do diclorometano, a perda de outros componentes é muito provável (Toci et al., 2006). No entanto, embora existam vários estudos sobre a composição química do café integral, pouco se sabe sobre a composição do café descafeinado, principalmente em relação aos compostos bioativos que conferem tantos benefícios à saúde. Além disso, são escassas as informações sobre até quanto tempo após a extração da bebida este benefício à saúde é preservado.

Em vista do alto consumo de café no Brasil, de sua importância como fonte de compostos bioativos na dieta e do crescente mercado do café descafeinado, este estudo foi conduzido com o objetivo de determinar a qualidade sensorial de café descafeinado, os compostos bioativos (cafeína, trigonelina e ácido clorogênico) em cafés integrais e descafeinados, antes e após a torração, e a estabilidade destes compostos bioativos após a extração da bebida.

\section{Material e Métodos}

Foram utilizadas amostras de café arábica (Coffea arabica L.), provenientes da safra 2006/2007, fornecidos por uma empresa de comercialização de São Paulo (Brasil). Os cafés foram preparados pelo método de via úmida (cereja descascado). A amostragem foi realizada pela empresa, com a coleta de grãos oriundos de várias sacas de café. Foram feitas, no total, três repetições de $5 \mathrm{~kg}$ cada. A descafeinação de $50 \%$ das amostras foi realizada pela própria empresa.

As amostras de café foram torradas em torrador de laboratório (Probat modelo BRZ 6 - Brasil), no grau de torração médio. $\mathrm{O}$ processo de torração iniciouse a $150^{\circ} \mathrm{C}$, segundo recomendações da Associação Americana de Cafés Especiais (AACE), e o ponto de torração final foi determinado pela tonalidade de cor final, aferida visualmente, e de forma instrumental com o colorímetro (Chromameter-2 Reflectance, Minolta, Osaka, Japão). Em seguida, os grãos torrados foram moídos (moinho elétrico Pinhalense, ML-1, Brasil) em granulometria fina (20 mesh), empacotados 
em embalagens de polietileno e alumínio, selados e armazenados a $-20^{\circ} \mathrm{C}$ até a realização das análises.

Os grãos verdes foram moídos em granulometria fina, em moinho refrigerado a $4^{\circ} \mathrm{C}$ (Tecnal, modelo TE 631/2, Brasil), com auxílio de nitrogênio líquido.

Utilizaram-se como solventes para preparo da fase móvel: metanol e ácido acético glacial de grau cromatográfico. A água empregada no preparo da fase móvel, dos padrões e demais soluções, foi obtida por sistema de purificação e filtração Milli-Q (Millipore). As fases móveis utilizadas foram filtradas em sistema Millipore de filtração a vácuo, com membranas de 0,22 $\mu \mathrm{m}$ (Millipore), e degaseificadas por $30 \mathrm{~min}$ antes de sua utilização, em degaseificador Shimadzu, modelo DGU-2A.

Nas análises, foram empregados padrões (de grau analítico) da Sigma para a determinação de ácido clorogênico (ácido 1,3,4,5-tetraidroxicicloexanocarboxílico - 5-ACQ), cafeína (1,2,7-trimetilxantina) e trigonelina (1-metilpiridinium-3-carboxilato monoidrato).

A análise sensorial foi realizada por meio do método oficial brasileiro de classificação de café pela bebida, segundo a Instrução Normativa $n^{\circ}$, de 11 de junho de 2003, do Ministério da Agricultura, Pecuária e Abastecimento, conhecido como "prova-da-xícara" (Brasil, 2007). Tal procedimento foi realizado por oito provadores treinados, credenciados pelo Ministério da Agricultura, Pecuária e Abastecimento, que não tiveram conhecimento nem do aspecto do grão antes da torração e nem da sua origem. As amostras foram torradas em torrador Probat modelo BRZ 6 (Brasil), no ponto de torração clara ou americana. Em seguida, foram moídas em moinho elétrico Pinhalense.

Para a determinação dos teores de cafeína, trigonelina e ácido clorogênico (ácido 5-cafeoilquínico), foram utilizados procedimentos de extração com água quente, segundo Vitorino et al. (2001), com 0,5 g de café torrado e moído e $100 \mathrm{~mL}$ de água destilada. Após a extração, cada amostra foi subdividida em cinco partes: uma parte analisada logo após a extração (amostra 0); e as demais analisadas a cada uma hora, com a última parte analisada após 4 horas (amostras 1, 2, 3 e 4). O extrato final foi filtrado em membrana Millipore de $0,22 \mu \mathrm{m}$ e injetado diretamente no cromatógrafo.

As análises foram realizadas por cromatografia líquida de alta eficiência (CLAE), com o cromatógrafo da marca Shimadzu (modelo M10AVP), com coluna de fase reversa C-18 Shimadzu (100 $\mathrm{mm}$ de comprimento x $0.3 \mathrm{~mm} \mathrm{DI}$ ). O sistema encontrava-se acoplado a um detector espectrofotométrico UV/visível Shimadzu (modeloSPD-10A), conectadoporinterface(CBM-101) a um microcomputador para processamento de dados. As condições de análise utilizadas foram: fluxo de $1 \mathrm{~mL} \min ^{-1}$; fase móvel: metanol, água e ácido acético (20:80:1); temperatura ambiente; comprimento de onda de $272 \mathrm{~nm}$.

$\mathrm{O}$ delineamento experimental utilizado foi $\mathrm{o}$ inteiramente ao acaso, com esquema fatorial $4 \times 5$, com quatro tipos de café (verde integral, torrado integral, verde descafeinado e torrado descafeinado), cinco tempos de análise $(0,1,2,3$ e 4 horas após a extração) e três repetições para cada tratamento.

Os dados obtidos foram submetidos à análise de variância e comparados pelo teste de Tukey, a 5\% de probabilidade. Utilizou-se a análise de regressão para o desdobramento dos tempos, em cada tipo de café, quando significativo. As análises estatísticas foram feitas pelo programa SISVAR (Ferreira, 2000).

\section{Resultados e Discussão}

$\mathrm{Na}$ análise sensorial, os resultados encontrados foram semelhantes para todos os provadores. As principais características citadas para a amostra integral foram: café bebida dura, com corpo, aroma, acidez e retrogosto normais. $\mathrm{Na}$ amostra descafeinada, as características foram: café descaracterizado, sem acidez, retrogosto ruim e sabor de gordura. Foi observado que todas as características sensoriais, presentes na amostra integral, foram perdidas após o processo de descafeinação.

Os teores de trigonelina, ácido clorogênico (ácido 5-cafeoilq uínico) e cafeína foram calculados a partir dos cromatogramas obtidos para cada amostra. Os tempos de retenção dos três compostos de interesse identificados foram: trigonelina (3,12 min), ácido clorogênico (15,7 $\mathrm{min})$ e cafeína (17 min). O conhecimento prévio da concentração de trigonelina permite estimar o potencial de degradação para formação dos compostos voláteis e do ácido nicotínico. Durante a torração, a trigonelina sofre desmetilação e forma o ácido nicotínico (niacina), que pode chegar a teores próximos a $20 \mathrm{mg} 100 \mathrm{~g}^{-1}$ de café torrado. A niacina é precursora das coenzimas NAD e NADP, importantes em várias reações de oxidação (Aguiar et al., 2005). 
As concentrações de trigonelina, nas duas amostras utilizadas de cafés crus e torrados, nos diferentes tempos de análise, encontram-se na Figura 1. A quantidade de trigonelina extraída dos grãos crus variou entre 1,34 e 1,24 g $100 \mathrm{~g}^{-1}$ de café, na amostra classificada

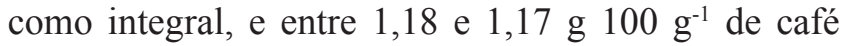
na amostra descafeinada. Nos cafés torrados, os teores de trigonelina variaram entre 0,55 e $0,54 \mathrm{~g} 100 \mathrm{~g}^{-1} \mathrm{de}$ café, na amostra classificada como integral, e entre

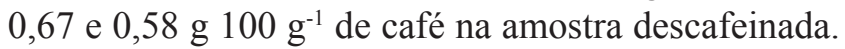
Monteiro \& Trugo (2005) relataram valor de

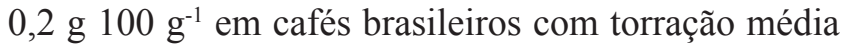
- inferior aos valores obtidos no presente estudo. Não foram constatadas diferenças significativas entre as amostras integrais e descafeinadas, o que demonstra que o processo de descafeinação por diclorometano não altera os teores de trigonelina.

Nos cinco tempos de análise utilizados, as concentrações de trigonelina não variaram nas amostras de café descafeinado verde e integral torrado, o que significa que até 4 horas após a extração, a bebida de café apresentava a mesma quantidade de trigonelina, enquanto nas amostras de café descafeinado torrado e integral verde, os teores de trigonelina reduziram com o passar do tempo. A redução ocorreu, provavelmente, em razão das reações químicas entre os diversos componentes presentes no café, pois a trigonelina é um composto não volátil. Esta diminuição de sua concentração, em algumas amostras, pode afetar a qualidade das bebidas, pois a trigonelina é um composto importante, tanto do ponto de vista sensorial como funcional.

Nas duas amostras avaliadas, houve redução significativa no teor de trigonelina após a torração.

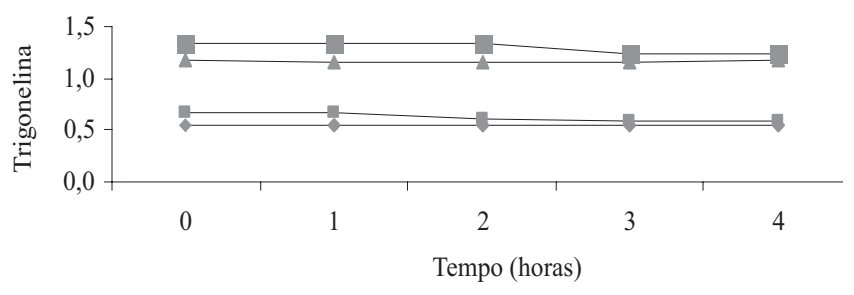

$$
\begin{aligned}
& \longrightarrow \text { Integral torrado } \quad-\text { Descafeinado torrado } \\
& \rightarrow-\text { Descafeinado verde }- \text { - Integral verde }
\end{aligned}
$$

Figura 1. Teores médios de trigonelina $\left(\mathrm{g} 100 \mathrm{~g}^{-1}\right) \mathrm{em}$ cafés integral e descafeinado, submetidos a dois tipos de processamento (cru e torrado) e cinco tempos de análise, após o processo de extração.
O café integral apresentou a maior degradação de trigonelina, em torno de $58 \%$, em comparação com aproximadamente $43 \%$ do café descafeinado e, possivelmente, foi a amostra com maior formação dos compostos voláteis e do ácido nicotínico.

Alguns trabalhos atribuem funções farmacológicas aos ácidos clorogênicos (5-ACQ), principalmente como antioxidante (Iwai et al., 2004; Duarte et al., 2005). Além do aspecto farmacológico, os ácidos clorogênicos são importantes na avaliação sensorial da bebida. Os ácidos clorogênicos são precursores importantes dos ácidos fenólicos livres e, por conseguinte, dos compostos fenólicos voláteis que participam da formação do aroma do café torrado (Moreira et al., 2000).

$\mathrm{Na}$ Figura 2, observa-se que em todas as amostras houve redução significativa na concentração do ácido 5-cafeoilquínico após a torração. Nos grãos do café integral verde, houve redução nos valores do 5-ACQ, com o decorrer do tempo de extração, o que não foi evidenciado para o 5-ACQ nas demais amostras. A quantidade de 5-ACQ extraído dos grãos crus variou entre 4,77 e 3,64 g $100 \mathrm{~g}^{-1}$ de café, na amostra classificada como integral, e entre 1,95 e $1,90{\mathrm{~g} 100 \mathrm{~g}^{-1}}^{-1}$ de café na amostra descafeinada. Nos cafés torrados, os

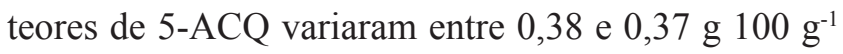
de café, na amostra classificada como integral, e entre

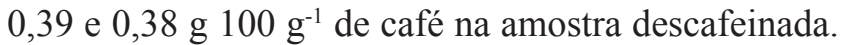
Segundo Araújo (2007), o conteúdo total de ácido clorogênico em café arábica é de $5,5 \mathrm{~g} 100 \mathrm{~g}^{-1}$, em média, valor superior aos encontrados no presente estudo. Foi observada diferença significativa entre as amostras integrais e descafeinadas, o que indica que

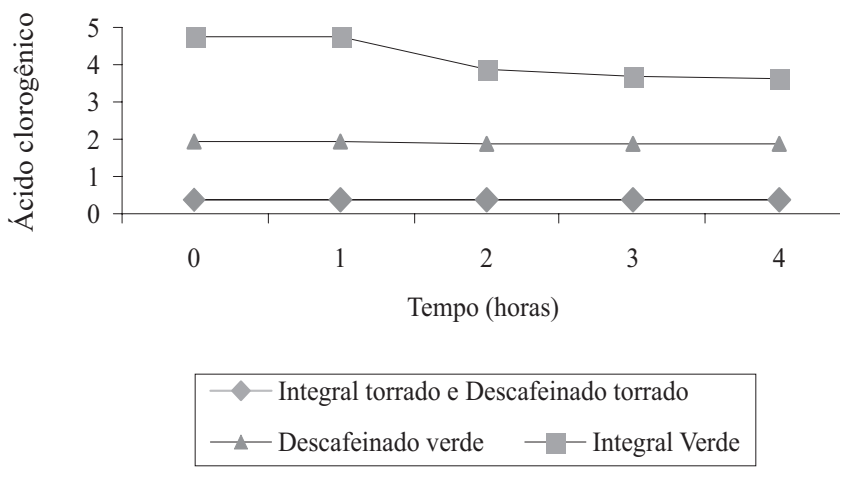

Figura 2. Teores médios de ácido clorogênico (g $\left.100 \mathrm{~g}^{-1}\right)$ em cafés integral e descafeinado, submetidos a dois tipos de processamento (cru e torrado) e cinco tempos de análise, após o processo de extração. 
o processo de descafeinação com diclorometano causa grande alteração nos teores de ácido clorogênico. Tal mudança pode interferir, significativamente, nas propriedades funcionais da bebida do café e em suas características sensoriais.

Nos dois cafés avaliados, não houve diferença significativa, quanto à cafeína, entre os valores de grãos crus (descafeinado: 0,003 g $100 \mathrm{~g}^{-1} \mathrm{e}$

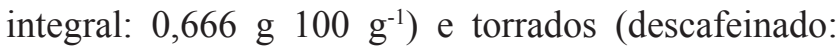

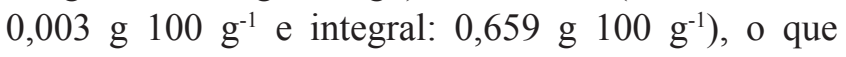
confirma sua estabilidade térmica durante a torração. $O$ valor encontrado para o grão integral cru encontrase dentro do que é estabelecido pela literatura, que

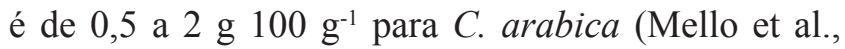
1992; Monteiro \& Trugo, 2005). Nos cinco tempos de análise utilizados, as concentrações de cafeína não apresentaram diferenças significativas, o que indica que a bebida de café apresentará a mesma quantidade de cafeína, até 4 horas após a extração.

O método utilizado para análise não detectou quantidades significativas de cafeína nas amostras descafeinadas, o que demonstra a eficiência do processo de descafeinação com diclorometano e enquadra os cafés utilizados dentro dos padrões estabelecidos pela legislação.

\section{Conclusões}

1. A descafeinação afeta a qualidade sensorial do café.

2. O processo de descafeinação com diclorometano e o processo de torração alteram a concentração dos compostos bioativos presentes na bebida do café.

3. A cafeína é o único composto bioativo estável, com o passar do tempo, após a extração da bebida.

\section{Agradecimentos}

Ao Conselho Nacional de Desenvolvimento Científico e Tecnológico, por concessão de bolsa.

\section{Referências}

AGUIAR, A.T.E.; FAZUOLI, L.C.; SALVA, T.J.G.; FAVARIN, J.L. Diversidade química de cafeeiros na espécie Coffea canephora. Bragantia, v.64, p.577-582, 2005.

ARAUJO, F.A. Café (Coffea arabica L.) submetido a diferentes condições de torrefação: caracterização química e avaliação da atividade antioxidante e sensorial. 2007. 130p. Tese (Doutorado) -
Universidade de São Paulo, Faculdade de Ciências Farmacêuticas, São Paulo.

ARAUJO, F.A.; MANCINI-FILHO, J. Compostos bioativos do café e seus benefícios à saúde. Revista Higiene Alimentar, v.20, p.60-65, 2006.

BRASIL. Ministério da Agricultura, Pecuária e Abastecimento. Instrução Normativa n. 8, de 11 de junho de 2003. Aprova o regulamento técnico da identidade e de qualidade para a classificação de café beneficiado grão cru. Disponível em: $<$ http;// www.ministerio.gov.br>. Acesso em: jan. 2007.

BRENELLI, E.C.S. A extração de cafeína em bebidas estimulantes: uma nova abordagem para um experimento clássico em química orgânica. Química nova, v.26, p.136-138, 2003.

CASAL, S.; OLIVEIRA, M.B.P.P.; ALVES, M.R.; FERREIRA, M.A. Discriminate analysis of roasted coffee varieties for trigonelline, nicotinic acid and caffeine content. Journal of Agricultural and Food Chemistry, v.48, p.3420-3424, 2000.

CLARKE, R.J.; MACRAE, R. Coffee: chemistry. New York: Elsevier Applied Science, 1985.

D’AVANZO, B.; SANTORO, L.; NOBILL, A.; LA VECCHIA, C. Coffee consumption and serum cholesterol. Preventive medicine, v.22, p.219-224, 1993.

DAGLIA, M.; PAPETTI, A.; GREGOTTI, C.; BERTÈ, F.; GAZZANI, G. In vitro antioxidant and ex vivo protetive activities of green and roasted coffee. Journal of Agricultural and Food Chemistry, v.48, p.1449-1454, 2000.

DE MARIA, C.A.B.; MOREIRA, R.F.A.; TRUGO, L.C. Componentes voláteis do café torrado. Parte I: compostos heterocíclicos. Química nova, v.22, p.209-217, 1999.

DUARTE, S.M.S.; ABREU, C.M.P.; MENEZES, H.C.; SANTOS, M.H.; GOUVÊA, C.M.C.P. Effect of processing and roasting on the antioxidant activity of coffee brews. Ciência e Tecnologia de Alimentos, v.25, p.387-393, 2005.

FARAH, A.; DONANGELO, C.M. Phenolic compounds in coffee. Brazilian Journal of Plant Physiology, v.18, p.23-26, 2006.

FERREIRA, D.F. Análises estatísticas por meio do Sisvar para Windows versão 4.0. In: REUNIÃO ANUAL DA REGIÃO BRASILEIRA DA SOCIEDADE INTERNACIONAL DE BIOMETRIA, 45., 2000, São Carlos. Programas e resumos... São Carlos, SP: UFSCar, 2000. p.255-258.

IWAI, K.; KISHIMOTO, N.; KAKINO, Y.; MOCHIDA, K.; FUJITA, T. In vitro antioxidant effects and tyrosinase inhibitory activities of seven hydroxycinnamoyl derivatives in green coffee beans. Journal of Agricultural and Food Chemistry, v.52, p.4893-4898, 2004.

KAWACHI, I.; COLDITZ, G.A.; STONE, C.B. Does coffee drinking increase the risk of coronary heart disease? Results from a meta-analysis. British Heart Journal, v.72, p.269-275, 1994.

KLATSKY,A.L.; ARMSTRONG, M.A.; FREEDMAN, G.D. Coffee, tea, and mortality. Annals of Epidemiology, v.3, p.375, 1993.

LICCIARDI, R.; PEREIRA, R.G.F.A.; MENDONÇA, L.M.V.L.; FURTADO, E.F. Avaliação físico-química de cafés torrados e moídos, de diferentes marcas comerciais, da região Sul de Minas Gerais. Ciência e Tecnologia de Alimentos, v.25, p. 425-429, 2005. 
MELLO, M.R.P.A.; MINAZZI-RODRIGUES, R.S.; CARVALHO, J.B.; SHIROSE, I. Estudo comparativo de métodos de extração para determinação de cafeína em café. Revista do Instituto Adolfo Lutz, v.52, p.89-95, 1992.

MONTEIRO, M.C.; TRUGO, L.C. Determinação de compostos bioativos em amostras comerciais de café torrado. Química nova, v.28, p.637-641, 2005.

MOREIRA, R.F.A.; TRUGO, L.C.; DE MARIA, C.A.B. Compostos voláteis do café torrado. Parte II - Compostos alifáticos, alicíclicos e aromáticos. Química nova, v.23, p.195-203, 2000.

SMITH, A.P.; KENDRICK, A.M.; MABEN, A.L. Effects of breakfast and caffeine on the performance and mood in the late morning and after lunch. Neuropsychobiology, v.26, p.198, 1992.
SOUZA, C.M.M.; SILVA, H.R.; VIEIRA-JUNIOR, G.M.; AYRES, C.L.S.C.; ARAUJO, D.S.; CAVALCANTE, L.C.D.; BARROS, E.D.S.; ARAUJO, P.B.M.; BRANDAO, M.S.; CHAVES, M.H. Fenóis totais e atividade antioxidante de cinco plantas medicinais, Química nova, v.30, p.351-355, 2007.

TOCI, A.; FARAH, A.; TRUGO, L.C. Efeito do processo de descafeinação com diclorometano sobre a composição química dos cafés arábica e robusta, antes e após a torração. Química nova, v.29, p.965-971, 2006.

VITORINO, M.D.; FRANÇA, A.S.; OLIVEIRA, L.S.; BORGES, M.L.A. Metodologias de obtenção de extrato de café visando a dosagem de compostos não voláteis. Revista Brasileira de Armazenamento, v.26, p.17-24, 2001.

Recebido em 10 de setembro de 2008 e aprovado em 28 de novembro de 2008 